\title{
Acerca de las influencias petrarquistas en España y en la naciente poesía novohispana
}

\author{
Alfredo DE Micheli \\ Instituto Nacional de Cardiología
}

Francesco Petrarca (1304-1374), originario de Arezzo en Toscana, fue el primer gran poeta lírico moderno, cuya influencia ha llegado hasta nuestros días. Sus obras Canzoniere y Trionfi dieron lugar en su propia tierra a la creación de una amplia variedad de poemas en lengua vernácula, influidos inicialmente por los Trionfi y después por los sonetos y las canciones del Canzoniere (Francisci Petrarchae poetae laureati rerum vulgarium fragmenta vel Nugae). Tal corriente de imitación, denominada ahora petrarquismo, se convirtió en un fenómeno poético de gran importancia primeramente en Italia y luego en toda Europa (Petrarca 2002: 117).

La tendencia de los petrarquistas consistía esencialmente en el recurrir a la naturaleza como fuente de las imágenes poéticas, en el autoanálisis sentimental, en la sensibilidad ante la belleza sensual, la melancolía frente a un amor inasequible, la referencia a los grandes poetas latinos y la innovación lingüística y métrica con base en el verso endecasílabo. Esta poesía supone el empleo de temas íntimos, como el amor platónico, el protagonismo de la naturaleza, el bucolismo y la mitología. Los petrarquistas italianos fueron ilustres personajes que vivieron entre los siglos XV y XVI, como el veneciano Pietro Bembo (1470-1547), autor de los "Asolani", diálogos de amor platónico dedicados a Lucrecia Borgia. Acentos petrarquistas se hallan también en Ludovico Ariosto, Baldassare Castiglione, Luigi Tansillo, Girolamo Parabosco, Serafino Aquilano, etcétera.

El gran éxito literario de un poeta mediocre como Serafino Aquilano (1466-1500) se debe sólo a su habilidad para presentar, en forma 
condensada, conceptos petrarquistas. Todos sus sonetos constituyen juegos de sorpresa, sus poemas son en realidad unos epigramas, por lo que logró volverse popular sobre todo gracias a sus estrambotes. Queda comprendido, por tanto, en el grupo de los llamados seiscientistas del Quattrocento o petrarquistas flamígeros, como Benedetto Gareth "el cariteo" (1450-1514), Antonio Tebaldi "el tebaldeo" (1463-1537), etc. Era el suyo un petrarquismo amanerado, tendiente a la artificiosidad. Los excesos de esta escuela provocaron un movimiento de reacción encabezado por Pietro Bembo, quien proponía la vuelta al Petrarca poeta, figura distinta a la del Petrarca manierista. En la cuarta década del siglo XVI, toda Italia se convirtió al bembismo.

Cabe mencionar, de pasada, que los sonetos de Aquilano, como los de Tebaldeo, son en general mediocres pero divertidos, mientras que los versos de los bembistas, aunque impecables en su aspecto formal, son generalmente monótonos. En el último tercio del siglo XVI, las obras de tres poetas napolitanos que gozaban de mayor renombre - Angelo di Costanzo (1507-1591), Bernardino Rota (1508-1575) y Luigi Tansillo (1510-1568) - se divulgaron en el volumen Rime diverse di molti eccellenti autori (1545-1560) a cargo de Girolamo Ruscelli, Ludovico Dolce y Luigi Domenichi. El paso desde estos poetas hacia Giambattista Marino (1569-1625), al que se debe el triunfo del culteranismo italiano o marinismo durante todo el siglo XVII, fue bastante breve.

En Inglaterra, con la única excepción de la traducción al inglés del soneto "S'amor non é, che dunque é quel ch'io sento?" (Si no es amor ¿qué es lo que yo siento?) (486), que Geoffrey Chaucer introdujo en su "Troilo y Crésida" en la década de 1380, no se encuentran alusiones al Canzoniere antes de 1527. En ese año sir Thomas Wyatt, de regreso de un viaje a Italia, llevó a la isla espíritu y formas de la poesía italiana, tradujo varios poemas de Petrarca y difundió así el petrarquismo y el empleo del soneto. Más tarde compuso versos al estilo de Petrarca sir Philip Sydney (1554-1586), poeta y político inglés.

En la Europa continental, el Canzoniere se dio a conocer igualmente en el siglo XVI. El poeta portugués Francisco Sá de Miranda (1480-1558) introdujo la métrica italiana en la lírica de su país. En Francia, se comenzó a traducir o imitar los poemas líricos de Petrarca en la primera mitad de la centuria. Al comienzo, la imitación solía ser de segunda mano, ya que los miembros de la "Pléyade" tomaban tanto del propio Petrarca como de los petrarquistas, por ejemplo Pierre Ronsard en sus "Amores" (1552). 
Ya en el siglo XV había habido en España algún intento de adoptar la métrica italiana por Micer Francisco Imperial (1372-1409), hijo de un comerciante genovés, y también por el marqués de Santillana (13981458), autor de "Sonetos hechos al itálico modo". Sin embargo, estos intentos quedaron sin fruto, dado que los autores no lograron dominar la acentuación del endecasílabo y componían más bien dodecasílabos.

La corriente poética petrarquista llegó a tierras hispanas gracias a la labor de difusión que hizo el humanista veneciano Andrea Navagero (1483-1529), embajador de la República de Venecia ante la corte del rey Carlos I. Dicho embajador impulsó al poeta Juan Boscán Almogáver, de Barcelona, a introducir la métrica italiana en la poesía castellana, en la senda de Petrarca. Pero tampoco el poeta barcelonés logró dominar el endecasílabo. Boscán, discípulo del humanista italiano Lucio Marineo Sículo (1460-1533), fue autor del poema "Historia de Hero y Leandro" en versos libres — derivado en gran parte de la "Favola di Leandro ed Hero" de Bernardo Tasso-, así como de la "octava rima", inspirada por las "Stanze" de Pietro Bembo. En ésta, al referirse a la virtud de amor, escribió Boscán: "Ésta guió la pluma al gran toscano / para pintar su Laura en su figura; / e hizo a miser Cino andar lozano / loando de Salvagia la hermosura". El gran toscano es Francesco Petrarca y Cino es el jurista Cino de Pistoia, poeta del dolce stil nuovo.

Fue el toledano Garcilaso de la Vega (1501-1536), gran amigo del poeta barcelonés, quien introdujo plenamente el petrarquismo en tierra española. Su lírica, guiada por un ideal arcádico expresado con melancólica serenidad, llegó a ser una de las cimas de la poesía castellana. Se manifiesta el petrarquismo sobre todo en sus composiciones poéticas del período 1529-1532, tiempo transcurrido entre la boda de su amada Isabel Freire y su destierro napolitano (De la Vega: 322323). Tal enfoque resalta en su canción II: "La soledad siguiendo [...]", evocadora del soneto XXXV de Petrarca: "Solo et pensoso i piú deserti campi [...]" (220). Más aún, debe tenerse presente la clara analogía entre el amor imposible, la soledad y el desencanto, propios del poeta aretino en lo referente a Laura, y los del toledano respecto a la bella portuguesa Isabel Freire (De la Vega: 323). La métrica italiana aparece constantemente en la obra de Garcilaso y la estrofa por él más empleada es justamente el soneto, en que alcanzó una gran perfección. 
Otros españoles siguieron la senda de la poesía italianizante. Así Hernando de Acuña (1520-1580), que tradujo a Ovidio, Gutierre de Cetina (1520-1557), bien conocido por su madrigal "Ojos claros y serenos" [...], y por sus sonetos. La influencia ejercida por los petrarquistas italianos en la España del siglo XVI ha sido estudiada cuidadosamente por Joseph Fucilla (1960). Amén de las numerosas imitaciones, hubo varias traducciones y adaptaciones al castellano. Sin embargo, ciertos autores hispanos, como Cristóbal de Castillejo (1490-1550) siguieron cultivando la poesía tradicional en octosílabos y versos de arte mayor. Los versos de Castillejo, en contra de Boscán y Garcilaso, han quedado como símbolo de la posición tradicionalista en la literatura española. De todos modos debe tenerse presente que, en promedio, más del $70 \%$ de los versos de una obra teatral del Siglo de Oro español está redactado en el sistema octosilábico. Y el segundo sistema métrico preferido por los dramaturgos es el endecasílabo en diversas combinaciones. La presencia de dicho verso y de las silvas — combinaciones del mismo con heptasílabos intercalados- constituye una herencia de la influencia italiana renacentista en la literatura hispana (Contreras: 22).

Durante el siglo XVI la naciente poesía lírica novohispana aparece como una prolongación de las voces de la madre patria. La lírica del poeta aretino encontró aquí ecos dignos así como, en otros géneros, se dejó sentir la influencia de Iacopo Sannazaro, Ludovico Ariosto y Torquato Tasso.

Hacia mediados de dicho siglo dos poetas sevillanos italianizantes, Juan de la Cueva y Gutierre de Cetina, llegaron a tierras del Anáhuac. El primero radicó en tierra mexicana de 1574 a 1577 y regresó a su ciudad natal, en donde siguió una brillante trayectoria como dramaturgo. El segundo se avecindó en la Nueva España y falleció en 1557, de muerte accidental. Este último, que había traducido una canción de Ludovico Ariosto "Quando il sol parte" [...], es considerado como el difusor, si no es que el introductor, en México de la corriente poética petrarquista tan en boga en la España del Renacimiento. Aunque aparezca encerrada dentro de los esquemas del petrarquismo y estructurada en moldes neoplatónicos, la obra de Cetina ejerció un gran influjo sobre los primeros poetas novohispanos: Francisco de Terrazas (10), Fernán González de Eslava, quien hacía representar sus coloquios y entremeses hacia 1574, y Carlos de Sámano, autor de la oda: "Ay, vanas esperanzas / en quien el pensamiento / fundó su gloria y todo mi 
contento!" Merece ser mencionado también el segundo marqués del Valle de Oaxaca, don Martín Cortés nacido verosímilmente en Cuernavaca hacia 1532, quien era poeta y mecenas de poetas. En sus bellas octavas reales predomina el motivo del desencanto: "De amor y de fortuna despreciado / de accidentes mortales combatido, / de congoja y dolor tan apurado, / que el seso le fallece y el sentido". Por su lado, en el "Túmulo imperial" —obra compuesta para las honras fúnebres de Carlos de Habsburgo, rey de España y emperador romano-germánico, impresa en 1560 en México- figuraban sonetos muy estimables y octavas que aplicaban el endecasílabo al antiguo orden de rimas de "arte mayor". Tales versos se deben en buena parte al Dr. Francisco Cervantes de Salazar (Toledo 1515-México 1575), uno de los primeros catedráticos de la flamante Universidad Mexicana.

Una antología de poetas peninsulares e hispanoamericanos renacentistas se recopiló en 1577 en México bajo el título Flores de baria poesía (1980). Esta colección, como señala Margarita Peña, sigue un hilo conductor decididamente petrarquista y contiene 359 composiciones de muchos autores de las escuelas sevillana y novohispana. El manuscrito original se halla ahora en la Biblioteca Nacional de Madrid, sección de manuscritos número 2973. Incluye 84 poemas de Cetina y 22 de Juan de la Cueva. La mayor parte imitan o se inspiran en versos de poetas italianos. Los sonetos 70, 215 y 281, según J. G. Fusilla, son imitaciones de motivos del propio Petrarca.

Los sonetos 69, 141, 191 y 211 derivan de motivos poéticos del petrarquista Luigi Tansillo, quien frecuentara la corte de Don Pedro de Toledo, virrey de Nápoles, y fuera compañero de armas y de viajes del hijo de éste, don García. Los sonetos 140 y 230 se inspiran en versos de Serafino Aquilano, los 278 y 320 tienen su origen en composiciones del poeta bembista veneciano Ludovico Dolce (1508-1568).

El soneto 143 "Mientras en mí la esperanza [...] florecía” evoca una rima del mantuano Baldassare Castiglione (1478-1529): "Cantai, mentre nel cor lieto fioría [...]" y el 302 "Cuitado, que en un punto lloro y río [...]", en opinión de J. G. Fucilla, se inspira en otro de Pietro Bembo; "Pace non trovo [...] / Lasso me ch'ad un tempo taccio e grido [...]", a través de Camoens: "Coitado! que em hum tempo choro e rio [...]". La fuente común de estos versos se halla probablemente en el soneto CXXXIV de Petrarca: "Pace non trovo, et non ó da far guerra; / e temo, et spero; et ardo, et son un ghiaccio [...]". El soneto 308 "Si no soco- 
rre Amor la frágil nave [...]" es un eco del de Francesco Coccio: "Deh porgi mano alla mia fragil barca [...]”. Y el 215: "En quál región? ¿En quál parte del suelo? / ¿En quál bosque? ¿En quál monte? ¿En quál poblado? / ¿Quál lugar tan remoto y apartado / puede ya a mi dolor poner consuelo?" recuerda el CLIX de Petrarca: "In qual parte del ciel, in quale idea / era l'exempio onde Natura tolse [...]”. Es distinto el remate. En Cetina: "No queráis a mi mal más experiencia, / sino que ya, como herida cierva, / do quier que voy, comigo va mi muerte". En Petrarca: "Non sa come Amor sana, et come ancide, / chi non sa come dolce ella sospira, / et come dolce parla, et dolce ride".

Se considera a Francisco de Terrazas, hijo de un conquistador que fuera mayordomo de Cortés, como el iniciador de la poesía novohispana. Don Marcelino Menéndez Pelayo lo definió como "el más antiguo poeta mexicano de nombre conocido". Y el entonces arzobispo de la capital virreinal, don Pedro Moya de Contreras, lo consideraba en 1574 como "un hombre de calidad, señor de pueblos y gran poeta". También Miguel de Cervantes se refería a él en el Canto de Calíope de La Galatea (1584): "Francisco, el uno de Terrazas, tiene el nombre / acá y allá tan conocido, cuya vena caudal nuevo / Hipocrene ha dado al patrio venturoso nido [...]".

El primer poeta novohispano fue autor de una epístola poética, diez décimas en honor de su amigo Fernán González de Eslava, nueve sonetos y fragmentos de un poema épico en octavas reales, que debía llevar como título "Nuevo Mundo y Conquista". Entre sus sonetos, los más bellos son los de indudable inspiración petrarquista. El soneto 120, "Dexad las hebras de oro ensortijado / que el ánima me tienen enlazada [...]" (Peña 1980), se inspira en uno de Luis Vaz de Camoens (15241580): "Tornai essa brancura a alva azucena [...]". Opina J. G. Fucilla que este último procede a su vez de un soneto italiano: "Rendete al ciel le sue bellezze sole [...]", atribuido al humanista modenés Francesco María Molza (1489-1544) quien, a más de sus hermosas elegías de amor en latín, compuso un cancionero de marcado influjo petrarquista. De acuerdo con J. G. Fucilla, tiene la misma fuente el soneto 121, anónimo, de Flores... Salvo algunas variantes, corresponde este último al número XXIX de Vadillo, discípulo y amigo de Cetina, y se inicia con el verso: "Volvedle el blancor al azucena [...]".

La antología Flores... comprende asimismo un soneto anónimo123, que representa una traducción casi literal de otro famoso de Petrarca 
(CLXXXIX de su cancionero) (1989: 608). El texto original comienza con la cuarteta: "Passa la nave mia colma d'oblio / per aspro mare, a mezzanotte il verno, / enfra Scilla et Caribdi, et al governo / siede'l signore, anzi 'l nimico mio [...]". Y el texto español: "Pasa la nave mia llena de olvido / por tempestuoso mar en el invierno / entre Scila y Caribdis, y el gobierno / lleva el Señor que tanto me ha afligido [...]”. Tal motivo poético reaparecerá siglos después en la época romántica, por ejemplo, en los versos desconsolados del poeta alemán Heinrich Heine, vertidos al italiano por Giosué Carducci:

Passa la nave mia con vele nere Con vele nere pel deserto mare. Ho in petto una ferita di dolore. Tu ti diverti a farla sanguinare. É come il vento perfido il tuo core E sempre qua e là presto a voltare. Passa la nave mia con vele nere, Con vele nere pel deserto mare.

Esto es:

Pasa mi nave con velas negras Con velas negras por el mar desierto.

Hay en mi pecho una herida dolorosa. $Y$ tu gozas en hacerla sangrar.

Es tu corazón pérfido como el viento Y siempre listo para dar vueltas.

Pasa mi nave con velas negras,

Con velas negras por el mar desierto.

Cabe mencionar, por otra parte, que en el inventario presentado a los oficiales del tribunal de la Inquisición por el librero Simón de Toro el 24 de enero de 1635, figuraba una colección de sonetos y canciones de Petrarca, vertidos al castellano por Enrique Garcés. Versos y prosas de Pietro Aretino estaban presentes en la biblioteca particular de Melchor Pérez de Soto quien fuera maestro mayor de nuestra catedral metropolitana en el período 1653-1655. Y una edición italiana de las obras poéticas del Aretino con fecha de 1563, proveniente de alguna biblioteca de la capital, se halla actualmente en la colección especial "Daniel Cosío Villegas” de El Colegio de México. 
Parece justificado agregar a esta breve nota un célebre axioma heideggeriano, de acuerdo con el pensamiento del filósofo dieciochesco Giambattista Vico: "Una lengua es la poesía original, en la que un pueblo expresa el Ser". Afirma, pues, el pensador alemán: "La poesía es el lenguaje primigenio de un pueblo histórico" (140). Por eso, es preciso entender la esencia del lenguaje por la esencia de la poesía. A su vez, el poeta laureado Saint-John Perse, en el discurso que pronunciara en Florencia con motivo del séptimo centenario del natalicio de Dante Alighieri (20 de abril de 1965) nos recuerda lo siguiente: "Poésie, science de l'être! Car toute poétique est une ontologie” (50). (Poesía ¡ciencia del Ser! Pues toda poética es una ontología; la traducción es mía).

\section{BibLIOGRAFÍA}

Cetina, Gutiérre De. Obras. México: Porrúa, 1977.

Contreras Soto, E. “Traduciendo a Los Acarnios", en Nova Tellus. 22.1. México: Universidad Nacional Autónoma de México, Instituto de Investigaciones Filológicas, Centro de Estudios Clásicos, 2004.

Fucilla, J. G. Estudios sobre el petrarquismo en España. Madrid: Revista de Filología Española. (LXXII, 1960).

Heidegger, Martin. "Hölderlin y la esencia de la poesía", en Arte y poesía. México: Fondo de Cultura Económica, 1985.

Palazón Mayoral, María Rosa; Margarita Peña y Ernesto Prado (comps.). Antología de la poesía en lengua española. Siglos XVI y XVII. México: Universidad Nacional Autónoma de México, Coordinación de Humanidades, Instituto de Investigaciones Filológicas, Centro de Estudios Literarios, 1999.

Peña, Margarita (ed.). Flores de baria poesía. México: Universidad Nacional Autónoma de México, Facultad de Filosofía y Letras, 1980.

- Flores de baria poesía: cancionero novohispano del siglo XVI. México: Fondo de Cultura Económica, 2004.

Petrarca, Francesco. Cancionero. I. Madrid: Cátedra, 2002.

- Cancionero II. Madrid: Cátedra, 1989.

Perse, Saint-John. Canto por un equinoccio y Discurso de Florencia. Trad. Elsa Cross, Lorena Fernández y Juan Carvajal. México: Universidad Nacional Autónoma de México / Instituto Nacional de Bellas Artes / Universidad Autónoma Metropolitana, 1987.

Terrazas, Francisco de, Poesías. México: Porrúa, 1941. (Biblioteca Mexicana 3). Vega, Garcilaso de la, Poesía. Madrid: Suma de Letras, 2002. 